discovered. The woman had no recollection of having swallowed any such thing, but said that she was in the habit of putting pins in her mouth.

Dr. Forbes Hawkes ${ }^{13}$ reports a case which has traumatism as its essential feature. An Italian labourer sewed a button on his vest and then stuck the threaded needle in his cravat. He indulged himself in true Italian style by fighting with some compatriots and received a sharp blow upon the epigastrium. He experienced a pricking sensation and a few days later noticed a scratch over the region of his stomach. Ten days later the man became quite ill, and all symptoms pointing to some grave intra abdominal condition laparotomy was resorted to. An abscess cavity was found beneath the liver and from this a pint and a half of greenish pus and one needle, threaded, were evacuated. Recovery followed.

Dr. Charles $\mathrm{H}$. Peck ${ }^{1+}$ removed a long upholstery tack from the appendix of a patient who had suffered from recurrent attacks of appendicular colic. He reports that while the appendix contained two fæcal concretions in addition to this foreign body, there was no inflammation.

The low mortality of cases of this nature is indeed surprising. In the two cases of insanity which I have quoted above it is distinctly stated that the presence of the foreign bodies did not contribute to the fatal result, in spite of the variety and multiplicity of the objects found.

The two cases reported by Dr. F. C. Bottomley ${ }^{15}$ would seem to offer negative proof of the statement that there is "safety in numbers." The first was that of a man, 56 years old, who had for four days suffered great pain in his back, high up between the shoulder blades, and had had several attacks of hematemesis during that time. When admitted to the Royal Free Hospital, London, the temperature was $102^{\circ} \mathrm{F}$. and for the two days between admission and death he suffered excruciating pain ard had repeated attacks of bloody vomiting. The patient's temperature ranged between $102^{\circ}$ and $104^{\circ}$ and he died after an illness of only six days' duration. The post-mortem findings were as follows. The upper dorsal portion of the aorta was perforated by a broken needle which also lay partly in a cavity between the aorta and the cesophagus. This cavity was small, was filled with blood and clot, and had a direct communication with the canal of the cesophagus. The second case was that of a woman, aged 35 years, who suddenly collapsed in the street. She was taken to the same hospital and examination revealed a tent-like, pulsating swelling over the cardiac area. A small incision was made over this and a needle, an inch and a half long, was removed. The woman regained consciousness and gave the meagre information that she had had pain in her left breast and had noticed a "tumour" for two days previously to her attack of syncope. Shortly after talking the patient became cyanosed and restless and died. The post-mortem findings were as follows. A pericardium distended with three-quarters of a pint of blood; a perforation a quarter of an inch in diameter situated at the base of the right ventricle, near the origin of the pulmonary artery; numerous scratches elsewhere upon the wall of the right ventricle.

An interesting necropsy finding is reported by Dr. Charles J. Cooke. ${ }^{16}$ A girl, aged eight years, swallowed a needle. Four days later Dr. Cooke found her suffering from meningitis, from which she died after having been under his care for six days. A necropsy showed a needle an inch and a half long imbedded firmly in the posterior wall of the pharynx on a level with the floor of the nasal cavity. It projected upward and backward. Manipulation dislodged it before accurate observation of the position of its upper end could be made, but Dr. Cooke believes that it penetrated and infected the sheath of some nerve and produced, by extension of the infection, the fatal meningitis which was demonstrated.

Such an interesting subject as the ingestion of pins and needlea could scarcely be dismissed without mentioning its connexion with the much-mooted question of the causation of cancer. Dr. Knott's paper, quoted above, contains this paragraph: "Godelias and Moniere have each recorded a case of cancerous stricture of the csophagus attributable to the swallowing of a pin a long time before. In each case the pin was found imbedded in the cancerous mass."

New York.

13 Annals of Surgery, 1903, vol. xxxvii., p. 950.

15
16 THE Med. Jour., 1896, vol, i., p. 1640.

\section{A STUDY OF FIVE CASES OF APPENDI-} COSTOMY.

BY J. LIONEL STRETTON, M.R.C.S. ENG., L.R.C.P. LOND.,

SENIOR SURGEON TO THE KIDDERMINSTER INFIRMARY AND CHILDREY'S HOSPITAL.

THE operation of appendicostomy has been described as of the simplest possible nature-.."a small button-hole incision through which the finger is passed and through which the appendix is withdrawn and fixed in position." This proceeding may be possible in some cases, but my experience is that the finding of the appendix is not so easily accomplished. There is no certainty as to its situation or condition. In three of $m y$ five cases (Cases 1,2 , and 5) it was curved and adherent, and in neither of them could it have been brought out of such an incision. I have found it preferable to make an opening sufficiently large to allow of easy manipulation, and latterly I have increased this in order that I may make a thorough examination of the abdominal contents. The increased risk is infinitesimal, while the conditions indicating the desirability of the performance of the operation are often obscure. With an incision of the length which I advise it is possible to fix the appendix in the most suitable position for the future passage of the catheter. I fix it outside by means of a pin passed through its mesentery and close the wound round it in layers, being careful not to constrict it too tightly. It is a disadvantage to put any sutures through its walls. It may be amputated at the end of 48 hours, but in future cases I shall leave it for a fortnight or three weeks unless there is pressing need for immediate irrigation. In Cases 1 and 5 its early removal was the cause of wound infection, a risk which must always be present, and if it occurs is a source of con. siderable trouble. It not only prolongs the process of healing but, owing to granulations and the retraction of the orifice of the appendix, it causes difficulty in passing the catheter and ultimate contraction of the opening. To show that this experience is not confined to myseif I may cite a case reported in THE LANCET of Dec. 28th, 1907 (p. 1819), by Dr. J. A. Pottinger, who says: "The catheter was at first removed between each occasion of irrigation, but it was found that even in 24 hours the wound closed so owing to the growth of granulations that it was somewhat difficult to find the opening and latterly a soft rubber instrument was used and left in." Since the operation was brought into prominence in this country I have performed it on tive different occasions. The following are the notes of the cases operated upon :-

CASE 1.-The patient, a female, aged 29 years, was admitied to the Kidderminster lnfirmary in October, 1905, on account of mucou colitis and obstinate constipation. She had suffered for 14 years and no treatment had benefited her.

On Nov.7th the appendix was exposed through the usual incision It was a long appendix, curved, horseshoe-shape, which nacessitated dividing the meso-appendix to bring it out. A suture on each side fixed it to the skin. On the second day after the operation the appendix was cut off level with the skin and irrigation was commenced with a satisfactory result. The orifice of the appendix sloughed and by the end of a week it was impossible to find a passage for the catheter. A second operation was performed in order to fix the orifice at the skin level, and a piece of indiarubber tube was left in for a few days. The patient complained of the pain caused by the passage of the catheter and became so unruly that it was found advisable to discharge her on Jan. 18th, 1906. The orifice to the appendix was then visible. She returned, however, in May and begged to have the part reopened. On examination the orifice had completely disappeared Under ether the cicatrix was excised and the orifice was discovere immediately beneath. It was sutured up to the skin and irrigation was commenced. The patient was soon able to pass the catheter to perform the irrigation herself and she derived great benefit therefrom. The bowels acted freely and there was much less mucus. She was discharged on the 25th. On March 28th, 1907, she returned again She had allowed the opening to contract almost to a pin point. With great difficulty a fine probe to contract almost to a pin point. With It was dilated up to No. 5 and irrigation was again commenced. She was cautioned as to the necessity of keeping the orifice patent and was cautioned as to the necessity of keeping the orifice patent and again discharged, but she had not the courage to continue the treat ment. She was seen again in October when the orifice was found to be contracted as it had been in March. It was evidently quite useless to persevere any further so I decided to perform an ileo-sigmoidostomy. CASE 2.- The patient, a female, aged 19 years, was admitted to the impossible to regulate the bowels by drugs and diet.

On April 3rd the appendix was exposed through an oblique incision; it was curved (horseshoe shaped) and the tip was adherent posteriorly. it was curved (horseshoe shaped) and the tip was adherent posteriorly. abdominal wound was closed in layers. On the fourth day after the aperation the appendix was cut off level with the skin; on the fifth day the pin was removed and irrigation of the bowel was commenced. The administration of a pint of water with balf an ounce of sulphate 
of magnesium was followed by an action in from five to ten minutes. Tarious solutions and drugs were tried and it was found that two drachms of olive oil was the most suitable. This acted perfectly and she was discharged on May 4th. I saw her about six months later and I have heard from her medical attendant quite recently. She continues perfectly well, the opening remains patent and gives her no trouble, perfectly well, the opening remain

CASE 3. - The patient, a female, aged 66 years, was admitted to the infirmary in May, 1906, on account of mucous colitis and constipation. infirmary in May, 1906, on account of mucous colitis and constipation. Her medical attendant was desirous that the operation of appendicostomy should be performed upon her. She was a well-nourished woman. of constipation, and of the passage of mueus. The abdomen was not distended or tender. Per rectum and per vaginam examination did not reveal anything. A large quantity of mucus was passed with the reveal anything. A large quantity of mucus was passed with the motions.

An operation was performed on May 11th in the same way as in Case 1. The appendix was cut off level with the skin on the fourth day and irrigation was then commenced. The administration of five pints of saline solution followed by two pints of solution of silver nitrate (one grain to a pint) acted immediately and brought away a large quantity of mucus and fæces. This was continued daily. Three days later the opening into the appendix was found to have retracted below the skin to the level of the deep fascia, probably owing to the commencement of irrigation before it was sufficiently adherent. It was still quite easy for us to pass the catheter but it would have been difficult for the patient herself to have done so. On June 3rd (just over three weeks ater) it was noticed for the first time that some of the Huid injected escaped by the side of the catheter. This amount increased daily and by the 7 th practically all the fluid injected increased daily and by the 7 th practically all the fluid injected returned through the opening. This caused a suspicion of some obste 9 th an incision was made in the left side to expose the sigmoid flexure. A malignant stricture was discovered and a colotomy was performed. The patient was discharged lived about six months and that the appendicostomy opening closed up and did not give any trouble.

up and did not give any trouble. infirmary in February, 1907, on account of obstinate constipation. She had had three attacks of pain in the right iliac region since September. Examination revealed some tenderness on deep pressure over the region of the cæcum. Nothing was discovered per vaginam or per rectum

On Feb. 5th the appendix was exposed through the usual incision. It contained a small concretion and it was brought out and beld in position by a pin through its mesentery. The wound was closed in layers, taking care not to strangulate the appendix or its mesentery. On the third day following the appendix with its contained concretion was cut off level with the skin. Irrigation was commenced on the day following. The patient was discharged on March 16th. She was much improved in health and could manage the irrigation quite easily. She has been seen several times since and she continues the irrigation which keeps her bowels regular and she feels quite well.

CASE 5.-The patient, a male, aged 50 years, was admitted to the infirmary in January, 1908. He had suffered for several years from infirmary in $J$

An operation was performed on Jan. 8th. The appendix was exposed An operation was performed on Jan, 8th. The appendix was exposed through the usual incision, three inches long, and the contents of the curved, necessitating partial division of its mesentery; it was fixed in the wound as in the previous case; it was cut off level with the skin the wound as in the previous case; it was cut off level with the skin
on the 1lth, and irrigation was commenced. Following this there was on the 1lth, and irrigation was commenced. Following this there was india-rubber catheter being kept in position. The effect of the irrigation was immediately satisfactory and all the bowel symptoms have disappeared.

In considering these five cases I think I can fairly claim that each of them derived benefit from the operation. In Case 3 it enabled us to diagnose the cause of the mucous colitis from which the patient had suffered and to perform a colotomy for its relief. The patient had been examined by several physicians without the condition being suspected and but for the appendicostomy it would have remained undiscovered until complete obstruction had occurred, when the risk of operation would have been far greater. The case indicates the importance of bearing in mind that mucous colitis may be only a symptom of organic disease. It is for this reason that I advocate intra-abdominal exploration at the time of operation. It has been suggested that the appendix can be dilated sufficiently to act in lieu of a colotomy. This would have been a suitable case for such a proceeding, but I was unable so to dilate it. From my experience I do not think that such a procedure is practicable in many cases.

The result of the treatment in the other four cases has been satisfactory so long as it has been continued. The mucus has disappeared within three weeks of irrigation. The fluid used consisted of two pints of saline solution followed by one pint of silver nitrate solution (one grain to the pint). At the end of three weeks the latter was omitted and a pint of saline solution only was used. In Case 2 it was found that two drachms of olive oil were sufficient to keep the bowels acting. I have seen this patient within the last month and find that this is still satisfactory.

Unfortunately many of these subjects are neurotio and it may be impossible to persuade them to continue the irrigation regularly. If they do not, the orifice is liable to contract; this is the more likely if there has been any wound infection at the time of operation. It is a difficult matter to dilate the orifice and when it is accomplished it will probably be allowed to contract again. The patient in Case 1 was an example of this class. In such cases a more radical procedure is indicated, but the preliminary performance of this operation does not materially add to the risk and gives patients a chance of relief by an operation with a lower mortality.

In none of the cases has there resulted the slightest discomfort. The orifice does not emit any discharge and is easily kept clean. The mucous colitis is easily controlled and the action of the bowels can be regulated with certainty.

Kidderminster.

\section{CONGENITAL HYPERTROPHIC STENOSIS OF THE PYLORUS AND ITS MEDICAL} TREATMENT.

BY GEORGE CARPEN'TER, M.D. LOND.,

CHAIRMAN OF COUNCLL OF THE SOCIETY FOR THE STUDY OF DISEASE IN CHILDREN; MEMBRE OORRESPONDANT DE LA SOCIÉTÉ DE PÁDIATRIE DE PARIS.

FOR some time I have been on the watch for a clinical example of pyloric obstruction in an infant which would convince me as to its undoubted hypertrophic nature and which would respond to medical treatment. The case which I presently shall relate satisfies those requirements. I have been well acquainted with dyspeptic troubles in infancy without pyloric hypertrophy which clinically give all the symptoms of that complaint except one important finding, and that is the pyloric tumour. Cases such as these I, too, have had my successes with medically. But if I were to enumerate all $\mathrm{my}$ experiences in that respect, then $I$ also would be able to bring to your notice a magnificent array of cases of congenital hypertrophic stenosis of the pylorus in place of this solitary example of a successful case medically treated.

It is but the other day, figuratively speaking, that serious attention was drawn to this condition, and the great number of cases that have fallen to the share of, and have been recorded by, some observers must be due to the inclusion in their statistics of the functional with the organic variety, of the very common with the rare, for it cannot be allowed that hypertrophic stenosis is any other than a rare condition. On the other hand, infantile cases of functional gastric disturbance with symptoms suggesting pyloric stenosis are very common. Some such explanation must be held accountable for the high percentage of cases which have fallen to the share of some writers on this subject in so short a time. But I must confess that I did not think it possible to cure such examples of congenital hypertrophic stenosis of the pylorus as have come within my clinical experience without surgical aid. In the cases of that complaint which I have treated the pyloric tumour was hard like gristle, cut like the cartilage of the knee, was felt through the abdominal wall, the infants were operated upon, and they all died. In the case which I am about to relate the patient presented symptoms and physical signs precisely similar to, and identical with, those just enumerated. By reason of his wasted state and the poor condition of his vitality he was not fit to undergo surgical operation and would, I doubt not, have died if he had been operated upon.

It is remarkable how many recorded cases there are where no pyloric tumour was felt and where the typical appearance was found either at operation or in the postamortem room. But notwithstanding these repeated failures to detect the tumour during life, I must confess that the diagnosis of congenital hypertrophic stenosis of the pylorus does not satisfy me unless the tumour be felt. Perhaps the failure to find it may in some cases have been due to want of experience of what to feel for, but I think that if greater care had been exercised in making the abdominal examinations the little tumours would not have so frequently remained undiscovered. Granted, however, that due care had been taken, I think I can offer another explanation for failure to feel the tumour. By the usual method of examination--that is, by palpationthe tumour is apt to recede from the fingers and to drop deep down into the abdominal cavity. Now, if in addition to the usual method of abdominal exploration the examiner grasps the abdominal parietes and the underlying parts with the

1 A paper read before the Society for the Study of Disease in Children on Jan. 17th, 1908. 